\title{
PERANCANGAN PROTOTIPE GENERATOR AXIAL MAGNET PERMANEN 3 PHASE
}

\author{
${ }^{(1)}$ Muhammad Suprapto, ${ }^{(2)}$ Saifullah Arief \\ ${ }^{(1)(2)}$ Teknik Mesin, Fakultas Teknik, Universitas Islam Kalimantan MAB \\ Jl. Adhiyaksa No. 2 Kayu Tangi, Banjarmasin \\ Email : muhammadsuprapto13@gmail.com,saifullahS2@yahoo.com
}

\begin{abstract}
Abstrak
Dengan menningkatnya kebutuhan akan energi fosil, maka semakin besar pula pencemaran lingkungan yang dihasilkan dari gas buangnya. Salah satu solusi dengan pengembangan energi baru dan terbarukan (EBT), Turbin angin savonius merupakan turbin angin dengan sumbu vertika yang memiliki banyak kelebihan diantaranya bentuk konstruksi yang mudah dibuat, tidak memerlikan kecepatan angin yang tinggi untuk mulai berputarnya. Turbin savonius memiliki kelemahan pada nilai efisiensi yang cukup rendah. Pada penelitian ini akan dilakukan perancangan turbin angin savonius dan pengujian secara eksperimen terhadap sudu bertingkat dan variasi overlap dengan parameter kecepatan putaran poros. Permodelan dan pengujian akan dilakukan di Laboratorium Teknik Mesin Universitas Islam Kalimantan Muhammad Arsyad AlBanjari, Banjarmasin. Kecepatan angin memiliki pengaruh yang bersar terhadap kinerja turbin angin savonius, semakin besar kecepatan angin maka putaran turbin juga semakain cepat. pada kecepatan angin $4 \mathrm{~m} / \mathrm{s}$ turbin savonius 1 tingkat memperoleh putaran shaft speed sebesar $252.7 \mathrm{Rpm}$. Sedangkan turbin angin savonius bertingkat 2 memperoleh putaran shaft speed sebesar $282.2 \mathrm{Rpm}$.
\end{abstract}

Kata kunci : Turbin Angin, Savonius, Sudu, Overlap.

\begin{abstract}
By increasing the need for fossil energy, the greater the environmental pollution generated from the exhaust gas. One solution to the development of new and renewable energy (EBT), the savonius wind turbine is a wind turbine with a vertical axis that has many advantages including a form of construction that is easy to make, does not release high wind speeds to start turning. Savonius turbine has a weakness in the value of efficiency that is quite low. In this research, Savonius wind turbine design will be conducted and experimentally tested on multilevel blades and overlap variations with shaft rotation speed parameters. Modeling and testing will be conducted at the Mechanical Engineering Laboratory of the Islamic University of Kalimantan Muhammad Arsyad Al-Banjari, Banjarmasin. Wind speed has an effect on the performance of the savonius wind turbine, the greater the wind speed, the turbine rotation is also faster. at $4 \mathrm{~m} / \mathrm{s}$ savonius turbine speed 1 level obtained a shaft speed rotation of $252.7 \mathrm{Rpm}$. While the savonius 2-level wind turbine obtained a shaft speed rotation of $282.2 \mathrm{Rpm}$.
\end{abstract}

Keywords: Wind Turbine, Savonius, Sudu, Overlap. 


\section{PENDAHULUAN}

Energi memiliki peranan penting hampir disemua aspek pada era modern saat ini, pengembangan energi terbarukan seperti energi angin, energi air dan energi surya dapat mengurangi ketergantungan kita pada bahan bakar fosil, yang semakin tahun ketersediaannya semakin menipis. (Debnath, Pinku .2014). di kalimantan selatan listrik yang digunakan bersumber dari PLN yang dominannya masih menggunakan bahan bakar fosil. Di Indonesia, khususnya kota Banjarmasin memiliki poteni kecepatan angin relatif yang rendah, maka dengan potensi kecepatan angin yang rendah turbin angin jenis vertikal cocok di kembangkan didaerah ini. Ada beberap tipe turbin vertikal namun yang cocok di gunakan pada kecepatan angin rendah yaitu jenis savonius karena memiliki self starting yang relatif rendah dibandingkan dengan jenis turbin vertikal lainnya.

Turbin angin savonius ini pertama kali di temukan oleh sarjana Finlandia bernama S. Savonius (1924). Pada turbin savonius ada beberapa komponen yang dapat di optimalisasi agar memperoleh efesiensi yan g tinggi, di antaranya jumlah sudu, bentuk sudu dan komponen lainnya. Pada penelitian tentang jumlah sudu turbin angin savonius (N.H. Mahmoud.2012), (M.Suprapto.2016) Turbin angin savonius denggan jumlah sudu 2 memiliki nilai efisiensi yang lebih tinggi dibandingkan dengan julah sudu 3 dan sudu 4. Bentuk sudu pada penelitian ini masih mengacu bentuk sudu turbin angin savonius tipe $U$ dengan setengah lingkaran.

Perencanaan dan pembuatan jumlah sudu pada turbin angin savonius ini mempunyai pengaruh yang sangat besar terhadap nilai shaft speed Halhal yang harus dipertimbangkan pada perencanaan dan pembuatan turbin angin savonius diantaranya adalah, kecepatan angin. dan tinggi Sudu turbin.

\section{TINJAUAN PUSTAKA \\ Energi Angin}

Energi adalah kemampuan melakukan kerja. Disebut demikian karena setiap kerja yang dilakukan sekecil apapun dan seringan apapun tetap membutuhkan energi. Menurut Kamus Besar Bahasa Indonesia (KBBI), energi didefiniskan sebagai daya atau kekuatan yang diperlukan untuk melakukan berbagai proses kegiatan. Energi merupakan bagian dari suatu benda tetapi tidak terikat pada benda tersebut. Energi bersifat fleksible artinya dapat berpindah dan berubah.

\section{Turbin Angin}

Turbin angin adalah alat yang berfungsi untuk mengubah energi kinetik angin menjadi energi gerak berupa putaran rotor dan poros generator untuk menghasilkan energi listrik. Energi gerak yang berasl dari angin akan diteruskan menjadi gaya gerak dan torsi pada poros generator yang kemudian dihasilkan energi listrik. Turbin angin merupakan mesin penggerak yang energi penggeraknya berasal dari angin.

Turbin angin adalah alat yang berfungsi untuk mengubah energi kinetik angin menjadi energi gerak berupa putaran rotor dan poros generator untuk menghasilkan energi listrik. Energi gerak yang berasl dari angin akan diteruskan menjadi gaya gerak dan torsi pada poros generator yang kemudian dihasilkan energi listrik. Turbin angin merupakan mesin penggerak yang energi penggeraknya berasal dari angin. Secara umum turbin angin sumbu Vertikal (TASV), khususnya turbin angin savonius memiliki kecepatan awal angin yang lebih rendah dibandingkan dengan turbin angin jenis lainnya 


\section{Sudu turbin savonius}

Sudu turbin angin yang terdiri dari baling-baling/ sudu merupakan bagian dari turbin angin yang berfungsi menerima energi kinetik dari angin dan merubahnya menjadi energi gerak (mekanik) putar pada poros penggerak. Pada sebuah turbin angin, baling-baling rotor dapat berjumlah 2, 3 atau lebih.

Turbin angin savonius merupakan jenis turbin angin yang paling sederhana, efisiensi sekitar \pm $20 \%$, turbin angin dapat berputar dan menghasilkan energi listrik pada kecepatan angin yang rendah dan tidak terpengaruh arah angin. Maka turbin ini sangat sesuai untuk di kembangkan dan diteliti sesuai dengan potensi yang ada di Indonesia, khususnya di daerah Kalimantan selatan.
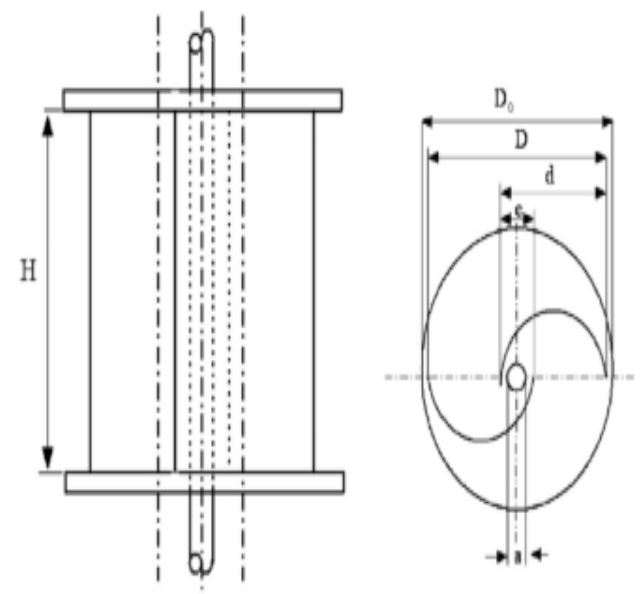

Gambar 1. Sudu Tubin Savonius

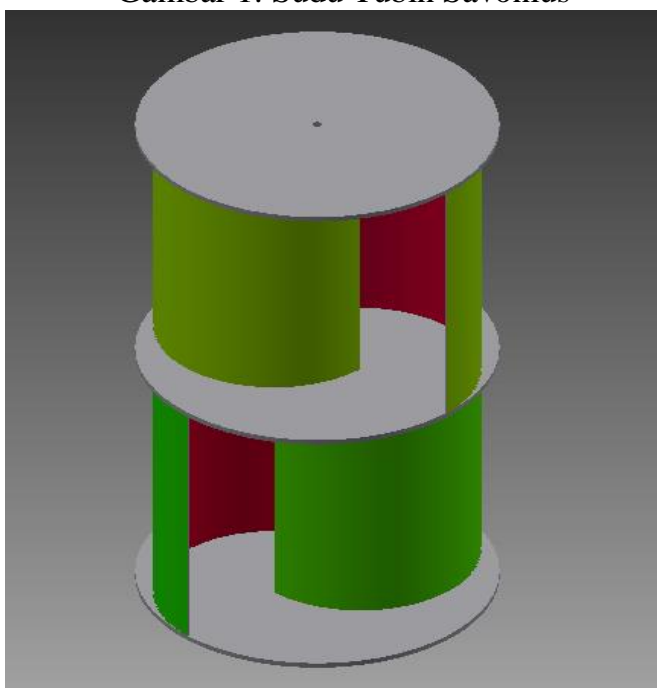

Gambar 2. Sudu model bertingkat

\section{Spesifikasi turbin}

Dari turbin savonius yang di buat di peroleh data spesifikasi teknis seperti ditunjukkan pada tabel 4.1 sebagai berikut.

Tabel 1. spesifikasi Turbin savonius

\begin{tabular}{|c|l|l|}
\hline No & \multicolumn{1}{|c|}{ Spesifikasi } & \multicolumn{1}{|c|}{ Keterangan } \\
\hline 1 & Jenis Turbin & $\begin{array}{l}\text { Turbin } \\
\text { Savonius } \\
\text { Bertingkat }\end{array}$ \\
\hline 2 & Jenis Putaran & Axial \\
\hline 3 & $\begin{array}{l}\text { Diameter end } \\
\text { plat }\end{array}$ & $0.3 \mathrm{~m}$ \\
\hline 4 & Material blade & Mika $2 \mathrm{~mm}$ \\
\hline 5 & Celah Udara & $50 \mathrm{~mm}$ \\
\hline 6 & Jumlah Sudu & 2 \\
\hline
\end{tabular}

Diagram alir penelitian

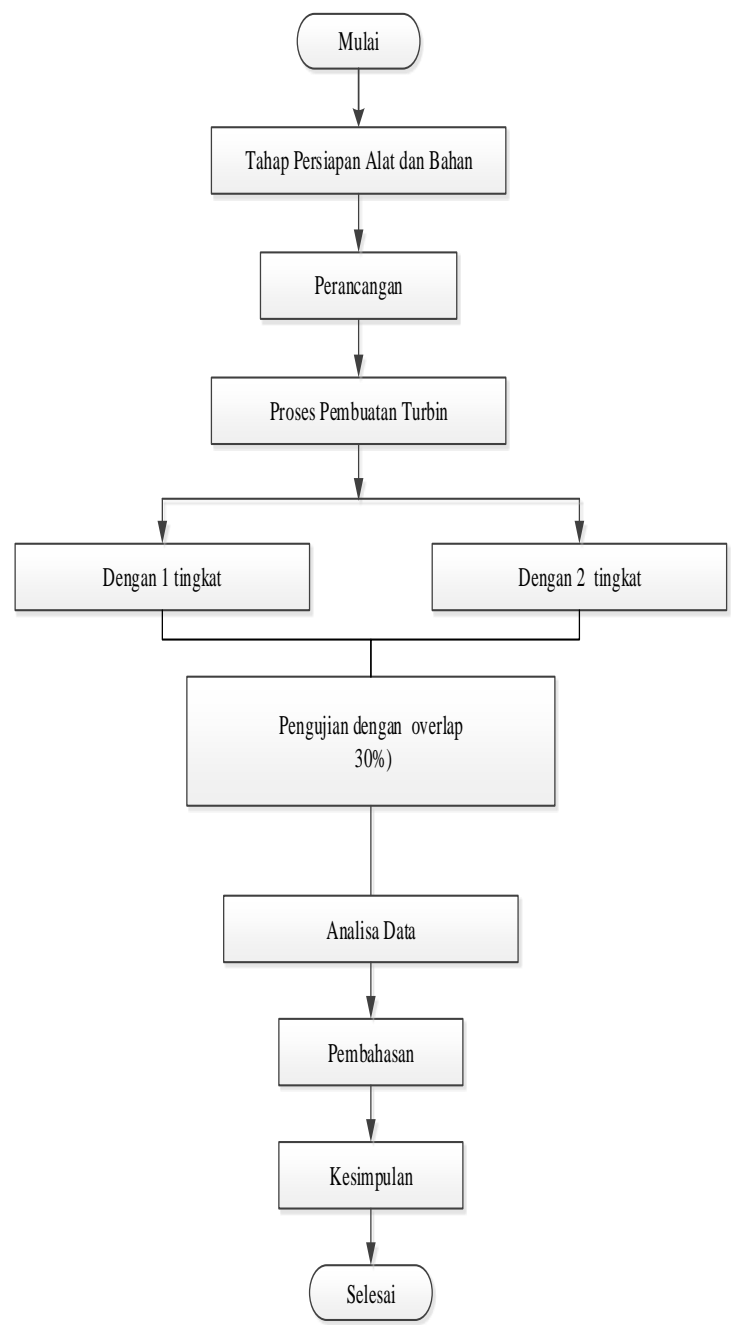

Gambar 3.1. Diagram Alir penelitian 
HASIL DAN PEMBAHASAN Perhitungan Daya Turbin Angin

Daya turbin savonius dapat dihitung dengan persamaan sebagai berikut: Efisiensi turbin savonius sebesar 20\% dengan kecepatan angin 2 $\mathrm{m} / \mathrm{s}$.

$$
\begin{aligned}
& p=\frac{1}{2} C p \rho A v^{3} \\
& p=\frac{1}{2}(0.2)(1.2)(0.18)\left(4^{3}\right) \\
& p=1.408
\end{aligned}
$$

Secara teoritis kecepatan shaft speed dapat dihitung dengan persamaan dibawah ini:

Perhitungan mengguakan nilai kecepatan angin $4 \mathrm{~m} / \mathrm{s}$.

$$
\begin{aligned}
& s s=\frac{60 . \lambda \cdot v}{\pi D} \\
& s s=\frac{60(1.5) 4}{(3.14)(0.3)} \\
& s s=382 \mathrm{Rpm}
\end{aligned}
$$

Tabel 2. hasil pengujian turbin savonius

\begin{tabular}{|c|c|c|c|c|c|c|}
\hline No & A & B & C & Daya & $\begin{array}{c}\text { Shaft } \\
\text { speed }\end{array}$ & Torsi \\
\hline 1 & 1 & 10 & 2 & 0.1759 & 161.7 & 0.00116 \\
\hline 2 & 1 & 20 & 3 & 0.5938 & 187.3 & 0.00337 \\
\hline 3 & 1 & 30 & 4 & 1.4077 & 252.7 & 0.00591 \\
\hline 4 & 1 & 10 & 3 & 0.5938 & 186.7 & 0.00338 \\
\hline 5 & 1 & 20 & 4 & 1.4077 & 246.7 & 0.00606 \\
\hline 6 & 2 & 30 & 2 & 0.1759 & 165.7 & 0.00113 \\
\hline 7 & 2 & 10 & 4 & 1.4077 & 250.7 & 0.00596 \\
\hline 8 & 2 & 20 & 2 & 0.1759 & 183.5 & 0.00102 \\
\hline 9 & 2 & 20 & 3 & 0.5938 & 191.6 & 0.00329 \\
\hline 10 & 2 & 30 & 4 & 1.4077 & 282.2 & 0.00391 \\
\hline
\end{tabular}

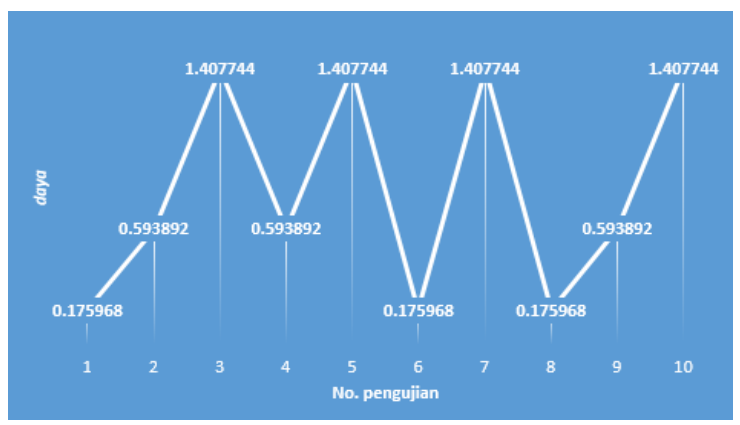

Grafik 1 daya turbin savonius
Dari grafik diatas nilai daya aktual turbin angin savonius hanya dipengaruhi nilai kecepatan angin. Pada kecepatan angin $2 \mathrm{~m} / \mathrm{s}$ dengan daya sebesar 0.175968 watt, kecepatan angin $3 \mathrm{~m} / \mathrm{s}$ dengan daya sebesar 0.593892 watt dan nilai tertinggi pada kecepatan angin $4 \mathrm{~m} / \mathrm{s}$ yaitu sebesar 1.407744 watt.

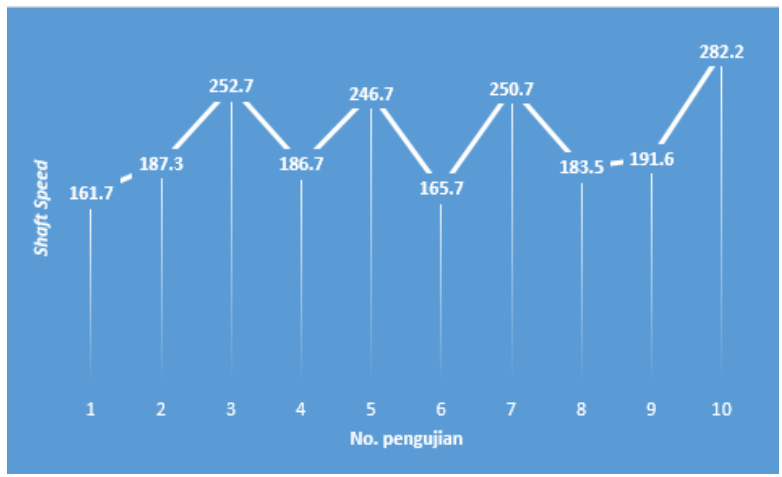

Grafik 2. putaran shaft speed

Pada pengukuran nilai putaran turbin savonius bertingkat, nilai putaran terendah pada pengujian/kombinasi ke1 dengan 1 tingkat, $10 \%$ overlap dan kecapatan angin $2 \mathrm{~m} / \mathrm{s}$ dengan kecepatan putaran 161.7 Rpm. Dan nila $=\mathrm{i}$ tertinggi pada pengujian ke/kombinasi ke-10 dengan 2 tingkat, $30 \%$ overlap dan kecapatan angin $4 \mathrm{~m} / \mathrm{s}$ dengan kecepatan putaran $282.2 \mathrm{Rpm}$

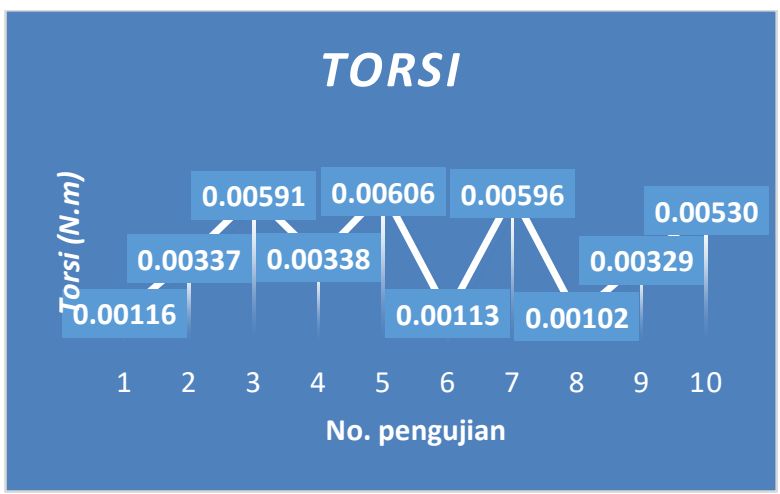

Grafik 3 Torsi

Nilai perhitungan torsi pada turbin savonius tertinggi yaitu 0.00606 N.m pada kombinasi ke-5, Dan nilai terendah pada perhitungan ke-8 dengan 0.00102 $\mathrm{Nm}$ 


\section{KESIMPULAN}

Berdasarkan hasil dari pengujian dan perhitungan teoritis turbin angin savonius bertingkat yang telah di analisa menggunakan metode eksperimen, maka dapat di ambil kesimpulan sebagai berikut :

1) Varisi jumlah sudu memiliki pengaruh terhadap putaran shaft speed dengan sudu dengan 1 tingkat memiiki kecepatan tertinggi 252.7 Rpm dan sudu 2 tingkat sebesar 282.2 Rpm.

2) Overlap memberikan pengaruh aliran udara pada turbin savonius dan kecepatan putaran tertinggi pada 282.rpm dan terendah pada $250 \mathrm{rpm}$ pada kondisi sudu bertingkat 2 dengan kecepatan angin $4 \mathrm{~m} / \mathrm{s}$.

3) Kecepatan angin memiliki pengaruh yang bersar terhadap kinerja turbin angin savonius, semakin besar kecepatan angin maka putaran turbin juga semakain cepat. pada kecepatan angin $4 \mathrm{~m} / \mathrm{s}$ turbin savonius 1 tingkat memperoleh putaran shaft speed sebesar 252.7 Rpm. Sedangkan turbin angin savonius bertingkat 2 memperoleh putaran shaft speed sebesar 282.2 Rpm.

\section{REFERENSI}

[1] Mohammed Hadi Ali. (2013). Experimental Comparison Study for SavoniusWind Turbine of two and Tree Blades At low Wind Speed. International Journalofmodern Engineering Research (IJMER), Vol.3-Issue $5 . \quad$ 2978-2986. LecturerUniversity of Mustansiriya.

[2] Sigurd J. Savonius, The wing-rotor in theory and practice, Publ. SAVONIUS \& CO., Helsingfors, Finland, 1-39, 1925

[3] M. Suprapto. Iskendar (2016) analisis Pengaruh jumlah sudu terhadap unjuk kerja pada turbin angin vertikal tipe savonius dengan metode taguchi.

[4] Sigemes, F., (2015) savonius wind rotor basics. University Centre in Svalbard (UNIS), Norway.

[5] Haqqqi. M. H, Gunawan. N dan Musyafa. A. 2013 Rancang Bangun TurbinAngin Vertikal Jenis Savonius dengan Variasi Jumlah Blade TerintegrasiCircular Shield untuk Memperoleh Daya Maksimum. Jurusan Teknik Fisika, Fakultas Teknologi Industri, Institut Teknologi Sepuluh Nopember(ITS).

[6] http://www.savonius.net/savoniusprinciple.html.

[7] https://en.wikipedia.org/wiki/Savoni us_wind turbine. 